\title{
The Effect of Arvanil on Prostate Cancer Cells Studied by Whole Cell High Resolution Magic Angle Spinning NMR
}

\section{Wei Li* and Bob M Moore II*}

Department of Pharmaceutical Sciences, College of Pharmacy, The University of Tennessee Health Science Center, Memphis, TN 38163, USA

\begin{abstract}
The transient receptor potential cation channel subfamily $\mathrm{V}$ member 1 (TRPV1) has recently gained attention as a potential target for the development of novel antineoplastic agents. It has been reported that the TRPV1 agonist arvanil has effective antiproliferative effects in studies using human breast cancer cells lines. In an extension of this research we have evaluated the $I_{50}$ values of arvanil in the prostate cancer cell lines PPC-1 (primary) and TSU (metastatic). Both TSU and PPC-1 cell lines are sensitive to treatment with arvanil. This result prompted our investigations into the changes in "cell metabolism" associated with prostate cancer progression and the effect of arvanil treatment. To this end, we have employed High Resolution Magic-Angle Spinning (HR-MAS) NMR spectroscopy on whole cells to determine the differences in the relative amount of cell metabolites and changes in small molecule metabolism following treatment of the TSU and PPC-1 cells with arvanil. We evaluated and confirmed that the existing "biomarkers" such as elevated tCho and decreased citrate in prostate cancer are well correlated with prostate cancer progression. In addition, metastatic TSU cells also contain elevated level of lactate and glutamine, and contain much less creatine. Upon treatment with arvanil, a number of biomolecules were found to undergo changes in intracellular levels during apoptosis. These data will potentially permit the further characterization of signaling pathways associated with TRPV1 activation as well as identifying new targets for the development of novel antineoplastic agents.
\end{abstract}

Keywords: High resolution magic spinning NMR; TRPV1; Arvanil; Prostate cancer

\section{Introduction}

Prostate cancer is the second most common cancer in men, exceeded only by lung and bronchial cancer. Based on the Cancer Facts and Figures 2013 compiled by American Cancer Society, an estimated 238,590 new cases of prostate cancer will be diagnosed in the United State and approximately 29,720 men will die of this disease. Accurate and timely diagnosis of prostate cancer is the key to control disease progression and effective early treatment, as up to $70 \%$ of patients are already in the advanced-stage of disease when initially seen.

It has been well recognized that with the tissue malignancy, there are detectable biochemistry changes. These changes can be observed in the metabolite profiles by NMR or MS and metabolite biomarkers can be identified [1-7]. High-Resolution Magic Angle Spinning (HRMAS) NMR has been used to study prostate cancer tissues and cells with much successfulness since its introduction in the late 1990s [8-12]. By spinning the sample at the "magic-angle", the dipolar couplings, chemical shift anisotropy and magnetic susceptibility changes are effectively reduced, and liquid-like spectra can be obtained in tissues and cultured cells. Tissues and cells can be well preserved during and after the HRMAS NMR experiments [10,13-16].

The Transient Receptor Potential cation channel subfamily V member 1 (TRPV1) has recently gained attention as a potential target for the development of novel antineoplastic agents [17-20]. It has been reported that the TRPV1 agonists have effective antiproliferative effects in studies using human breast, prostate, pancreatic, osteosarcoma, and gastric cancer cells lines [21-25]. In an extension of this research we have evaluated the $\mathrm{IC}_{50}$ values of arvanil, a TRPV1 agonist, in the prostate cancer cell lines PPC-1 (primary) and TSU (metastatic). We also employed High Resolution Magic-Angle Spinning (HR-MAS) NMR spectroscopy on whole cells to determine the differences in the relative amount of cell metabolites and changes in small molecule metabolism following treatment of the TSU and PPC-1 cells with arvanil.

\section{Materials and Methods}

Cell culture and bioassay of arvanil on prostate cancer cell lines

PPC-1 cells were purchased from American Type Cell Culture and TSU cells were a gift from Dr. James Dalton, GTx Inc. Memphis, TN. Cells were seeded in 96 -well polystyrene flat-bottom plates $(7,500$ cells/well) at 70 80\% confluency in a $100 \mu \mathrm{l}$ total volume of complete growth media (FK12K medium containing 10\% fetal bovine serum) and incubated overnight at $37^{\circ} \mathrm{C}$ in an atmosphere of $5 \% \mathrm{CO}_{2}$ and $95 \%$ air to allow for adherence. The media were then replaced with serumfree media and the cultures were treated with escalating amounts of arvanil and cell death was analyzed at $18 \mathrm{~h}$, using the BioTek Synergy 2 Multidetection Microplate Reader (BioTek Instruments, Inc.). The percentage of viable cells present in the culture at each time point was calculated by comparing the absorbance value at $450 \mathrm{~nm}$ from the CCK8 assay (Dojindo Molecular Technologies) for each condition with untreated control cells. All assays were conducted per manufacturer's protocol. All described values represent theaverage of three data points per determination and three independent determinations.

\section{NMR sample preparation}

Cells were harvested when cells are at 70 80\% confluence using Trypsin digestion. After washed with $\mathrm{D}_{2} \mathrm{O} / \mathrm{PBS}$ for three times, the suspended cells were placed in a NMR nanotube (a total volume of 40 $\mu \mathrm{l})$ for HRMAS NMR measurements. In the study of arvanil treatment for prostate cancer cells, a concentration of $20 \mu \mathrm{M}$ of arvanil was used in the cell culture for various time periods before the cells were prepared for NMR measurement.

\section{HRMAS NMR measurement}

All HRMAS experiments were performed at $37^{\circ} \mathrm{C}$ on an Agilent

*Corresponding authors: Wei Li, Department of Pharmaceutical Sciences, College of Pharmacy, The University of Tennessee Health Science Center, Memphis, TN 38163, 847 Monroe Avenue, Room 327B, Memphis, TN 38163, USA, Tel: +1-901 448-7532; Fax: +1-901-448-6828; E-mail: wli@uthsc.edu

Bob M Moore II, 847 Monroe Avenue, Room 327D, Memphis, 38163, USA, Tel: +1901-448-6085; Fax +1-901-448-6828; E-mail: bmoore@uthsc.edu

Received January 29, 2014; Accepted February 21, 2014; Published February 24, 2014

Citation: Li W, Moore II BM (2014) The Effect of Arvanil on Prostate Cancer Cells Studied by Whole Cell High Resolution Magic Angle Spinning NMR. Mod Chem appl 2: 119. doi:10.4172/2329-6798.1000119

Copyright: (c) $2014 \mathrm{Li} \mathrm{W}$, et al. This is an open-access article distributed under the terms of the Creative Commons Attribution License, which permits unrestricted use, distribution, and reproduction in any medium, provided the original author and source are credited. 


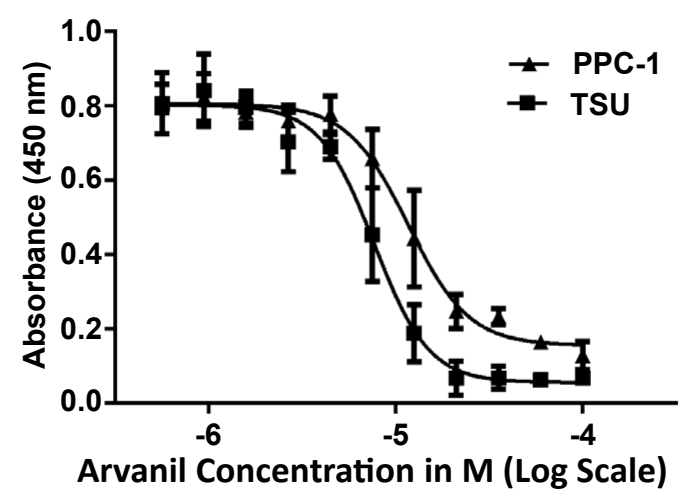

Figure 1: Dose response curves for PPC-1 and TSU cell lines treated with arvanil

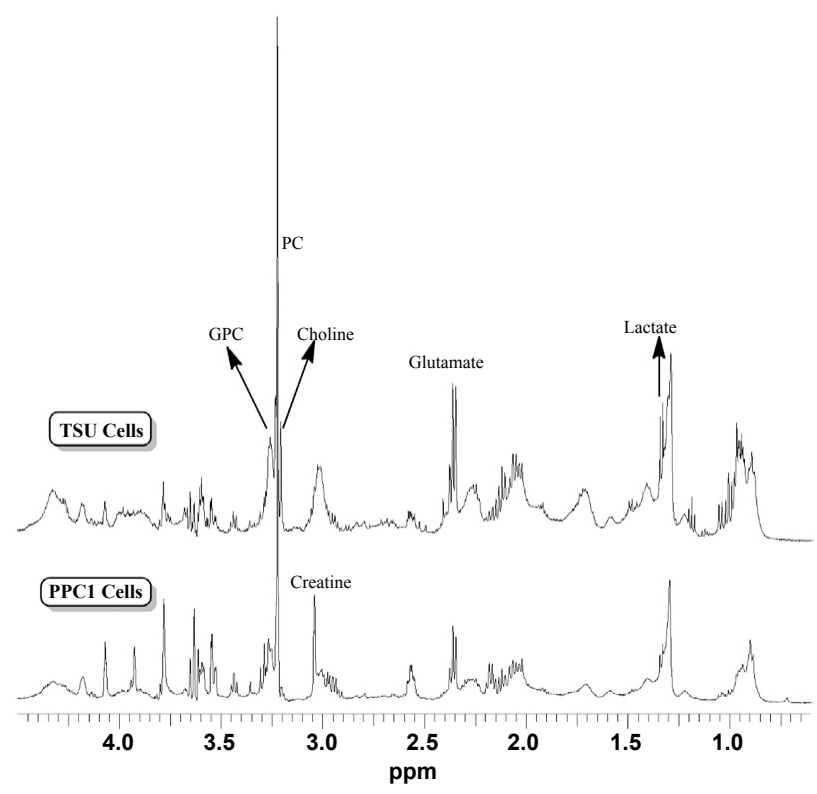

Figure 2: Baseline metabolic profiles of PPC1 (a primary prostate cancer cell line) and TSU (a metastatic prostate cancer cell line) as determined by HRMAS NMR. Major differences include significantly decreased level of creatine and increased levels of lactate, glutamate, choline, phosphocholine (PC), and glycerophosphocholine (GPC) in the metastatic cell line TSU compared with primary cell line PPC1.

(formerly Varian) Unity Inova-500 NMR spectrometer using a $4 \mathrm{~mm}$ gHX Nanoprobe (Agilent Technologies, Santa Clara, CA). Temperature was controlled with a general accuracy of $\pm 0.1^{\circ} \mathrm{C}$. Sample spinning rate was set to $2500 \mathrm{~Hz}$ with a general accuracy of $\pm 2 \mathrm{~Hz}$. A rotorsynchronized Carr-Purcell-Meiboom-Gill (CPMG) pulse sequence [26] was used to function as a $T_{2}$ filter to suppress the broad signals from macromolecules. The inter-pulse delay was synchronized with the rotor ration and the total $\mathrm{T}_{2}$ filter was set to $20 \mathrm{~ms}$. Water suppression sequence was incorporated into the pulse sequence to suppress the remaining water signal. The 90 degree pulse varies between $5.8 \mu$ s and $6.5 \mu$ s and was measured and adjusted individually for each sample. The number of transients was 400 , with a repetition delay of 3.5 seconds.

Data were processed with Varian's standard VNMR software with $1 \mathrm{~Hz}$ line-broadening before Fourier transformation and phase adjustment. All spectra were referenced to the TSP in the solution.
Quantitation was performed based on the integral value of TSP in each sample.Metabolites assignments were based on literature data, 2D NMR and spiking cells with authentic compounds.

For control experiments, growth media and arvanil were dissolved in appropriate NMR solvents and NMR spectra were acquired on a 5 mm HCN inverse probe.

\section{Results and Discussion}

\section{Arvanil treatment potently suppresses prostate cancer cell proliferation}

To select a working concentration of arvanil for our HRMAS studies the $\mathrm{IC}_{50}$ was determined in the primary cancer cell line PPCland a metastatic cell line TSU (Figure 1). Both PPC-1 ( IC $_{50} 11.8$ $\mu \mathrm{M})$ and TSU $\left(\mathrm{IC}_{50} 7.68 \mu \mathrm{M}\right)$ cell viability was significantly reduced by increasing concentrations of arvanil. An $\mathrm{IC}_{90}$ of $\sim 20 \mu \mathrm{M}$ was selected for the studies to maximize cellular responses in an effort to enhance the detection of specific metabolites associated with arvanil treatment. Thus, this study compared the metabolic profiles of primary and metastatic prostate cancer cells to evaluate biomarkers in prostate cancer prognosis (Figure 1).

\section{Primary PPC1 and metastatic TSU prostate cancer cells have different metabolic profiles revealed by HRMAS NMR}

Before evaluating the effects of arvanil treatments on metabolite changes in prostate cancer cells, we first compared the basal level metabolic profiles for the two prostate cancer cell lines tested. The metabolic profiles of the two prostate cancer cells were measured using HRMAS NMR. PPC1 cells represent primary prostate cancer stage, and TSU cells represent metastatic prostate cancer stage. Figure 2 shows the HRMAS ${ }^{1} \mathrm{H}$ NMR spectra of the two prostate cancer cell lines. These metabolite profiles are well comparable to that obtained from HRMAS measured on tissues directly with slightly higher resolution. This is expected because cultured prostate cancer cells are more homogeneous compared with whole tissues directly from patients (Figure 2).

Compared with primary prostate cancer PPC1 cells, the metastatic TSU cells contain significantly elevated levels of lactate $(1.33 \mathrm{ppm})$, choline $(3.20 \mathrm{ppm})$, glutamate $(2.36 \mathrm{ppm})$ and reduced level of creatine (3.05 ppm and $3.85 \mathrm{ppm}$ ). The three choline metabolites (free choline, phosphocholine and glycerol phosphocholine) are clearly resolved in the both of the spectra, and the total amount of choline (tCho), which includes these three metabolites, are significantly higher in the metastatic TSU cells than that in primary PPC1 cells. There is no detectable citrate in either of the prostate cell lines.

Elevated tCho and decreased amount of creatine have been consistently observed in literature reports, and the ratio of tCho/ creatine has been suggested as a biomarker in prostate cancer diagnosis. Increased amount of tCho in both PPC1 and TSU cells is likely due to accelerated membrane synthesis of rapidly dividing cancer cells, although altered phosphorous metabolism in cancer cells may also be responsible. The larger amount of tCho in TSU compared with that in primary cancer PPC1 cells indicates that tCho is directly related to prostate cancer cell malignancy as well as its metastatic progress. Citrate, which is abundant in normal prostate tissues and cells, is below the detection level in both of the prostate cancer cell lines, consistent with literature reports $[27,28]$.

\section{Effect of arvanil treatment on the prostate cancer cell lines}

When treated with arvanil for different time periods, changes 


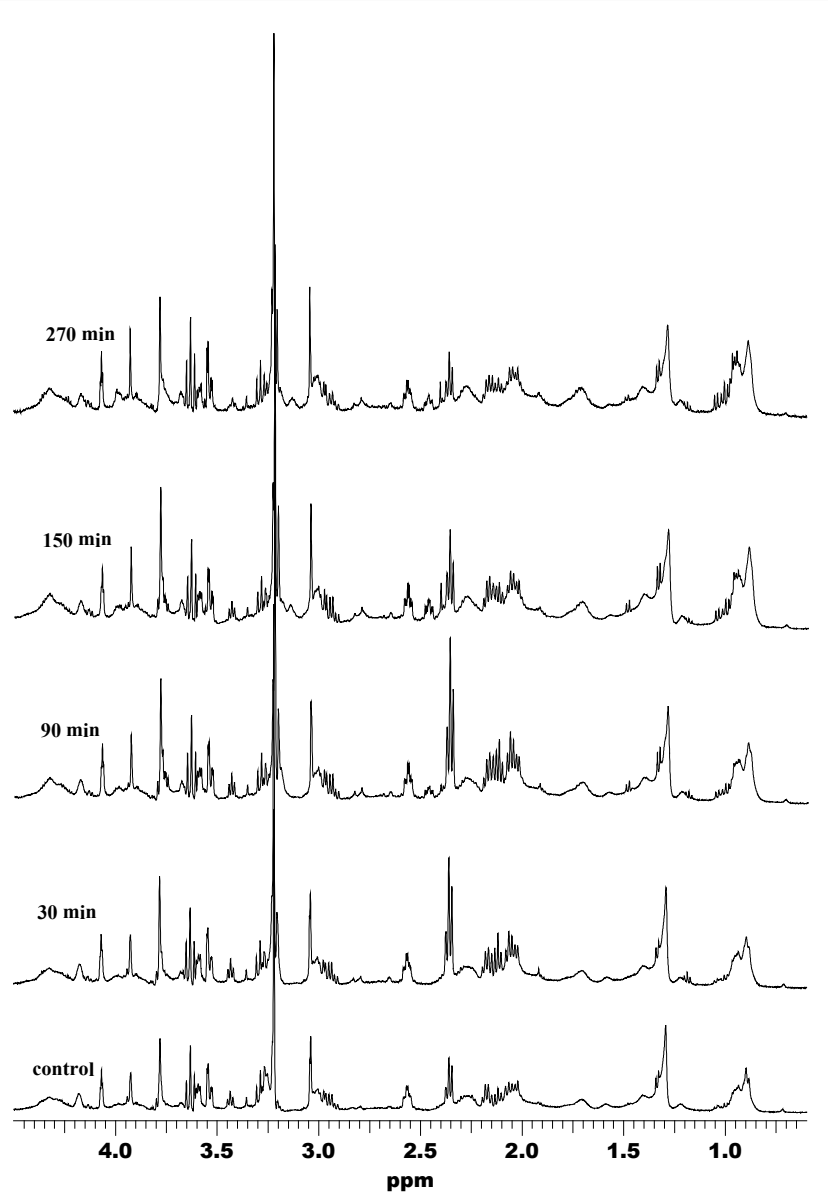

Figure 3: Metabolic profile changes as a function of arvanil treatment time for primary PPC1 prostate cancer cells.

in metabolic profiles in the choline regions were observed for both PPC1 and TSU cell lines. Figures 3 and 4 show the metabolite profiles following treatment with arvanil in PPC1 and TSU cells, respectively.

There was a consistent trend of metabolite changes up to 150 minutes of arvanil treatment. At 270 minutes, a substantial amount of cells has been found dead under a microscope, and after washing, the amount of cells that contribute to the NMR signal drops significantly. Compared with vehicle controls, the absolute amount of choline increases for both PPC1 and TSU cells, as shown in Figure 5. The relative amount of choline expressed as a ratio to the total choline also increased upon arvanil treatment (Figure 5).

The mechanism whereby metabolism of choline, PC, and GPC in prostate cancer is affected by treatment with TRPV1 remains to be determined. It has been reported that capsaicin, a TRPV1 agonist, induces apoptosis in PC-3 cells and inhibits tumor growth in vivo. The mechanism of the effects was reported to involve reactive oxygen species, mitochondrial depolarization followed by caspase- 3 mediated apoptosis [25]. Although we have not examined mitochondrial function in our studies, the time dependent changes in choline, PC, and GPC are consistent with mitochondria dysfunction. Specifically, increased Cho metabolism has been demonstrated in diseases manifesting mitochondrial dysfunction $[29,30]$ and has been used as a biomarker for this impairment [31]. The differences in the PPC-1 and TSU Cho profiles may reflect induction of choline kinase which has been reported in metastatic cancer cells [32]. Thus, HRMAS has demonstrated not only the ability to detect potential biomarkers, as noted above, but also provides a potential window into the metabolic vents associated with anti-cancer drug activity.

\section{Conclusion}

Our HR-MAS analyses on whole cells confirmed that several existing biomarkers (e.g. increased tCho and decreased citrate) correlate well with stages of prostate cancer progression. Compared with early stage prostate cancer cells (PPC1 cells), metastatic prostate cancer cells (TSU cells) also contain much less creatine but contain higher level of lactate and glutamine, consistent with the observations that more aggressive cancer cells are generally more dependent on aerobic glycolysis for their proliferation [33]. When prostate cancer cells were treated with arvanil, several molecules were found to undergo changes in intracellular levels during apoptosis. Collectively, these data provide

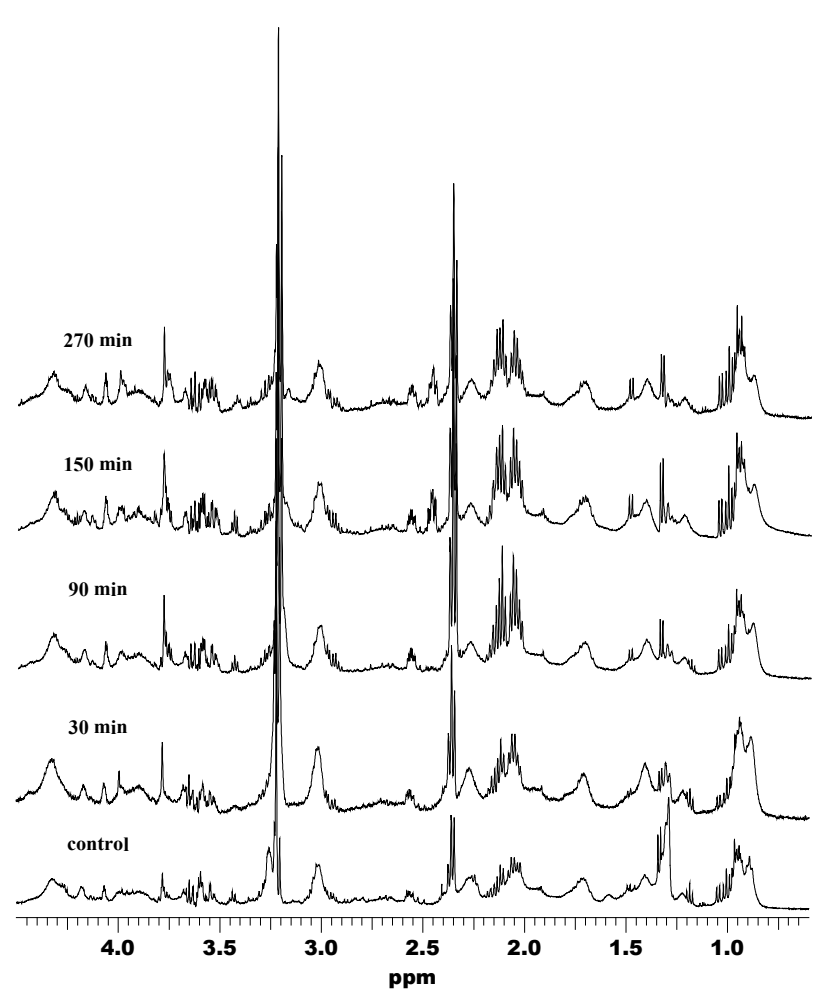

Figure 4: Metabolic profile changes as a function of arvanil treatment time for metastatic TSU prostate cancer cells.
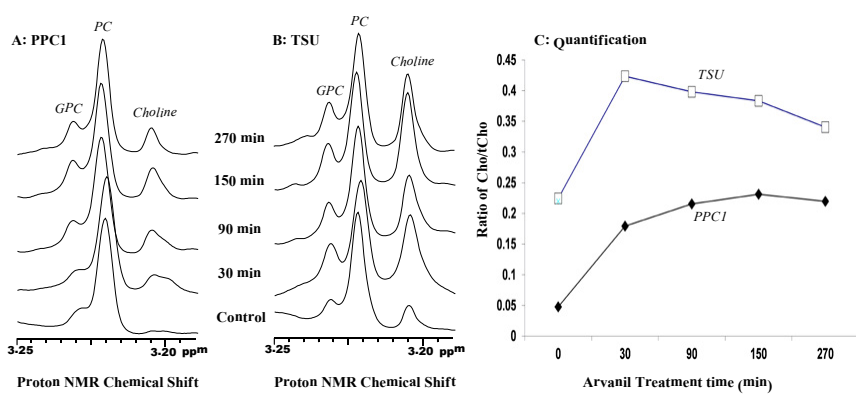

Figure 5: Choline changes upon treatment with arvanil in prostate cancer cells. Panel A: levels of choline, PC, and GPC as a function of arvanil treatment time for PPC1 cells. Panel B: levels of choline, PC, and GPC as a function of arvanil treatment time for TSU cells. Panel C: the ratio of choline over total choline (choline+PC+GPC) as a function of treatment time. 
rationale to characterize signaling pathways associated with TRPV1 activation and to identify new potential targets for the development of novel antineoplastic agents.

\section{Acknowledgement}

The work is supported by funds from College of Pharmacy, the University of Tennessee Health Science Center.

\section{References}

1. Bansal N, Gupta A, Mitash N, Shakya PS, Mandhani A, et al. (2013) Lowand high-grade bladder cancer determination via human serum-based metabolomics approach. J Proteome Res 12: 5839-5850.

2. Blaise BJ, Lopez C, Vercherat C, Lacheretz-Bernigaud A, Bayet-Robert M, et al. (2013) Metabolic expressivity of human genetic variants: NMR metabotyping of MEN1 pathogenic mutants. J Pharm Biomed Anal

3. Lefort N, Brown A, Lloyd V, Ouellette R, Touaibia M, et al. (2013) 1H NMR metabolomics analysis of the effect of dichloroacetate and allopurinol on breast cancers. J Pharm Biomed Anal .

4. Jobard E, Pontoizeau C2, Blaise BJ2, Bachelot T3, Elena-Herrmann B4, et al (2014) A serum nuclear magnetic resonance-based metabolomic signature of advanced metastatic human breast cancer. Cancer Lett 343: 33-41.

5. Mimmi MC, Finato N, Pizzolato G, Beltrami CA, Fogolari F, et al. (2013) Absolute quantification of choline-related biomarkers in breast cancer biopsies by liquid chromatography electrospray ionization mass spectrometry. Anal Cell Pathol (Amst) 36: 71-83.

6. Ritchie SA, Akita H, Takemasa I, Eguchi H, Pastural E, et al. (2013) Metabolic system alterations in pancreatic cancer patient serum: potential for early detection. BMC Cancer 13: 416

7. Wen T, Gao L, Wen Z, Wu C, Tan CS, et al. (2013) Exploratory investigation of plasma metabolomics in human lung adenocarcinoma. Mol Biosyst 9: 2370 2378.

8. Stenman K, Stattin P, Stenlund H, Riklund K, Gröbner G, et al. (2011) H HRMAS NMR Derived Bio-markers Related to Tumor Grade, Tumor Cell Fraction, and Cell Proliferation in Prostate Tissue Samples. Biomark Insights 6: 39-47.

9. van Asten JJ, Cuijpers V, Hulsbergen-van de Kaa C, Soede-Huijbregts C, Witjes JA, et al. (2008) High resolution magic angle spinning NMR spectroscopy for metabolic assessment of cancer presence and Gleason score in human prostate needle biopsies. MAGMA 21: 435-442.

10. Cheng LL, Wu C, Smith MR, Gonzalez RG (2001) Non-destructive quantitation of spermine in human prostate tissue samples using HRMAS $1 \mathrm{H}$ NMR spectroscopy at 9.4 T. FEBS Lett 494: 112-116.

11. Rocha CM, Barros AS, Gil AM, Goodfellow BJ, Humpfer E, et al. (2010) Metabolic profiling of human lung cancer tissue by $1 \mathrm{H}$ high resolution magic angle spinning (HRMAS) NMR spectroscopy. J Proteome Res 9: 319-332.

12. Griffin JL, Blenkiron C, Valonen PK, Caldas C, Kauppinen RA (2006) High-resolution magic angle spinning $1 \mathrm{H}$ NMR spectroscopy and reverse transcription-PCR analysis of apoptosis in a rat glioma. Anal Chem 78: 15461552.

13. Cheng LL, Chang IW, Louis DN, Gonzalez RG (1998) Correlation of highresolution magic angle spinning proton magnetic resonance spectroscopy with histopathology of intact human brain tumor specimens. Cancer Res 58: 18251832.

14. Chen W, Lou H, Zhang H, Nie X, Lan W, et al. (2011) Grade classification of neuroepithelial tumors using high-resolution magic-angle spinning proton nuclear magnetic resonance spectroscopy and pattern recognition. Sci China Life Sci 54: 606-616.

15. Mazzei P, Piccolo A, Nugnes L, Mascolo M, De Rosa G, et al. (2010) Metabolic profile of intact tissue from uterine leiomyomas using high-resolution magicangle-spinning ${ }^{1} \mathrm{H}$ NMR spectroscopy. NMR Biomed 23: 1137-1145.

16. Andronesi OC, Blekas KD, Mintzopoulos D, Astrakas L, Black PM, et al. (2008) Molecular classification of brain tumor biopsies using solid-state magic angle spinning proton magnetic resonance spectroscopy and robust classifiers. Int Oncol 33: 1017-1025.

17. Masumoto K, Tsukimoto M, Kojima S (2013) Role of TRPM2 and TRPV1 cation channels in cellular responses to radiation-induced DNA damage. Biochim Biophys Acta 1830: 3382-3390.
18. Liberati S, Morelli MB, Nabissi M, Santoni M, Santoni G (2013) Oncogenic and anti-oncogenic effects of transient receptor potential channels. Curr Top Med Chem 13: 344-366.

19. Vinuesa AG, Sancho R, García-Limones C, Behrens A, ten Dijke P, et al. (2012) Vanilloid receptor-1 regulates neurogenic inflammation in colon and protects mice from colon cancer. Cancer Res 72: 1705-1716.

20. Bödding M (2007) TRP proteins and cancer. Cell Signal 19: 617-624.

21. Park SY, Kim JY, Lee SM, Jun CH, Cho SB, et al. (2014) Capsaicin induces apoptosis and modulates MAPK signaling in human gastric cancer cells. Mol Med Rep 9: 499-502.

22. Cho WH, Lee HJ, Choi YJ, Oh JH, Kim HS, et al. (2013) Capsaicin induce apoptosis in MG63 human osteosarcoma cells via the caspase cascade and the antioxidant enzyme system. Mol Med Rep 8: 1655-1662.

23. Lin S, Zhang J, Chen H, Chen K, Lai F, et al. (2013) Involvement of endoplasmic reticulum stress in capsaicin-induced apoptosis of human pancreatic cancer cells. Evid Based Complement Alternat Med 2013: 629750.

24. Sanchez MG, Sanchez AM, Collado B, Malagarie-Cazenave S, Olea N, et al. (2005) Expression of the transient receptor potential vanilloid 1 (TRPV1) in LNCaP and PC-3 prostate cancer cells and in human prostate tissue. Eur $\mathrm{J}$ Pharmacol 515: 20-27.

25. Sánchez AM, Sánchez MG, Malagarie-Cazenave S, Olea N, Díaz-Laviada (2006) Induction of apoptosis in prostate tumor PC-3 cells and inhibition of xenograft prostate tumor growth by the vanilloid capsaicin. Apoptosis 11: 89-99.

26. Meiboom S, Gill D (1958) Modified Spin-Echo Method for Measuring Nuclear Relaxation Times. Rev Sci Instrum 29: 688-691.

27. Giskeødegård GF, Bertilsson $H$, Selnæs KM, Wright AJ, Bathen TF, et al (2013) Spermine and citrate as metabolic biomarkers for assessing prostate cancer aggressiveness. PLoS One 8: e62375.

28. Kline EE, Treat EG, Averna TA, Davis MS, Smith AY, et al. (2006) Citrate concentrations in human seminal fluid and expressed prostatic fluid determined via $1 \mathrm{H}$ nuclear magnetic resonance spectroscopy outperform prostate specific antigen in prostate cancer detection. J Urol 176: 2274-2279.

29. Farber SA, Slack BE, Blusztajn JK (2000) Acceleration of phosphatidylcholine synthesis and breakdown by inhibitors of mitochondrial function in neuronal cells: a model of the membrane defect of Alzheimer's disease. FASEB $\mathrm{J} 14$ 2198-2206.

30. Michel V, Yuan Z, Ramsubir S, Bakovic M (2006) Choline transport for phospholipid synthesis. Exp Biol Med (Maywood) 231: 490-504.

31. Meyerhoff DJ, MacKay S, Constans JM, Norman D, Van Dyke C, et al. (1994) Axonal injury and membrane alterations in Alzheimer's disease suggested by in vivo proton magnetic resonance spectroscopic imaging. Ann Neurol 36: 40-47.

32. Glunde K, Shah T, Winnard PT Jr, Raman V, Takagi T, et al. (2008) Hypoxia regulates choline kinase expression through hypoxia-inducible factor- 1 alpha signaling in a human prostate cancer model. Cancer Res 68: 172-180.

33. Lunt SY, Vander Heiden MG (2011) Aerobic glycolysis: meeting the metabolic requirements of cell proliferation. Annu Rev Cell Dev Biol 27: 441-464. 